\title{
Analyzing the Effects of Production Control on Logistic Targets with Web-Based Simulation Model
}

\author{
Guenther Schuh, Till Potente, Sascha Fuchs, and Christina Thomas \\ Laboratory for Machine Tools and Production Engineering, \\ Steinbachstrasse 19, 52074 Aachen, Germany \\ \{g.schuh, t.potente, s.fuchs, c.thomas\}@wzl.rwth-aachen.de
}

\begin{abstract}
Manufacturing companies are facing the challenge to cope with individualized process chains in spite of high market dynamics. In order to achieve high process efficiency by realizing logistic targets, two main leverages can be identified: adjustment of production structure and configuration of production control. The production structure represents the layout and arrangement of machines, the organization of production processes as well as the information and material flow. Once installed, it is often set for a long period of time and therefore represents the basis for further elements in a production environment such as production control. The dilemma of production planning and control is to achieve high process efficiency, low throughput times and good planning confidence while customers demand short productlifecycles, an increasing product variety and a growing individualization of products. Within this paper, a simulation-based study about the effects of production structure and production control to logistical targets is introduced.
\end{abstract}

Keywords: production control, production structure, simulation model, manufacturing control principles.

\section{Introduction}

Manufacturing companies are facing the challenge to cope with individualized process chains in spite of high market dynamics. In order to achieve high process efficiency by meeting logistic targets, two leverages exist: adjustment of production structure and configuration of production control. The production structure represents the foundation of production processes. It determines the layout and arrangement of machines, the organization of production processes as well as the information and material flow. Once installed, it is often set for a long period of time and therefore represents the basis for further elements in a production environment such as production control. The dilemma of production planning and control is to achieve high process efficiency, low throughput times and good planning confidence while customers demand short product-lifecycles, an increasing product variety and a growing individualization of products. In order to realize robust processes within a turbulent environment, the challenge of production control is determined by an 
adequate adaption of control mechanisms according to production's conditions. Within this paper, a simulation-based study about the effects of production structure and production control to logistical targets is introduced and an approach to standardize simulating processes is given.

\subsection{Challenges in Production Structure}

Following Ulrich, a company can be understood as a complex structure with an interdisciplinary character. Financial, material and information flows connect a company to its environment [1]. The internal structure of a company resembles a system. The elements of this system are people and machines. Furthermore, materials can be interpreted as objects to be transformed, money as an instrument of payment and information as a condition for goal-oriented activities of each production element. In order to make the system a functional one, the mentioned elements have to be arranged in an appropriate way. This arrangement can be defined as the system structure in which elements have a certain relationship to each other [2]. The definition of a production structure can be derived from the system definition by Ropohl. He describes every system with a working and an information system [3]. Therefore, the production structure determines the layout and arrangement of machines, the organization of production processes as well as the information and material flow. I.e. both, visual elements in the physical production process such as machines and their capacity as well as organizational elements like the lot size or work in process, are included. Finally, production structure can be defined as the foundation of production processes.

The challenge of production structure is to enhance robust processes on the one hand and on the other hand to enable adaptive and versatile structures which can be changed according to market dynamic. Once installed, a production structure is often set for a long period of time and therefore represents the basis for further actions in a production environment such as production control.

\subsection{Challenges in Production Planning and Control}

The challenge of production control is to achieve high process efficiency, low throughput times and good planning confidence despite of a turbulent, customeroriented environment with short product-lifecycles, an increasing product variety and a growing individualization of demands [4]. To overcome this problem of transparency, a multitude of IT-tools were developed: Supply Chain Management (SCM), Enterprise Resource Planning (ERP) and Manufacturing Execution Systems (MES) are examples of software tools to deal with growing complexity [5]. Thereby, the main challenge in production control is on the one hand to fulfil the classic logistic targets defined by Wiendahl [6] such as low stocks, short throughput times and a high adherence to delivery dates, but following Goldratt [7] also to maximize the throughput at a minimum of operating costs despite any turbulence. In order to react to economic crises or booms, production has to be flexible. This urges 
companies to react to these circumstances in a faster and more efficient way than their competitors [8]. Consequently, the configuration of control task is a main challenge for operators involved in production control.

\subsection{The Tasks of Production Control}

The configuration of control tasks follows the four functions of production control defined by Lödding: Order generation, order release, sequencing and capacity utilization control [9].

Order generation generates production orders and determines plan figures for accesses and exits. Trigger for an order generation may be customer orders, material removals from the finished goods warehouse or the production program. As psychological effects and intransparent parameters can lead to major bullwhip effects in the value stream, methods of forecasting need to be carefully applied. Order release determines the date of the start of production. In fact it influences work in process and capacity utilization and therefore determines the average throughput time of orders. The sequencing of waiting queues has the main influence on the distribution of throughput times and thus the adherence of delivery dates. The sequence is defined by certain rules, which assigns priorities to orders. More detailed methods of sequencing become necessary if the structure of the production process becomes more complex, the variety of processes increases or if the volatility of the market demand is very high. Finally, capacity utilization control has a major influence on productivity and production costs. It pre-determines necessary capacities for production while taking disturbances and planning errors into consideration. Beyond, flexible capacities in form of additional machines or resources help to ensure on-time delivery.

An expansion of these four tasks of production control described by Lödding is the value stream oriented concept described by Schuh [10]. It integrates the logic of the production control by Lödding. In contrast to most other approaches which mainly consist of control strategies for job release and sequencing at machines, the concept of value stream oriented production control also includes job creation.

The basic framework for the configuration of production control is a three layer model that starts with the value stream on the shop floor (see Fig. 1). The value stream represents the production process. The intention is to display segments of equal production control configuration along the production process. The production control layer describes the configuration of the production control and the information needed both from the master data, order data and from the shop floor. Manufacturing master data and order data are the input for all planning and control activities. They consist of work plans, bill of material and customer demands represented in a master production schedule. The third layer allows the link between changes of the configuration of production control or on the shop floor and changes within master data, as data inconsistencies are often the origin of many problems in production control [11]. 


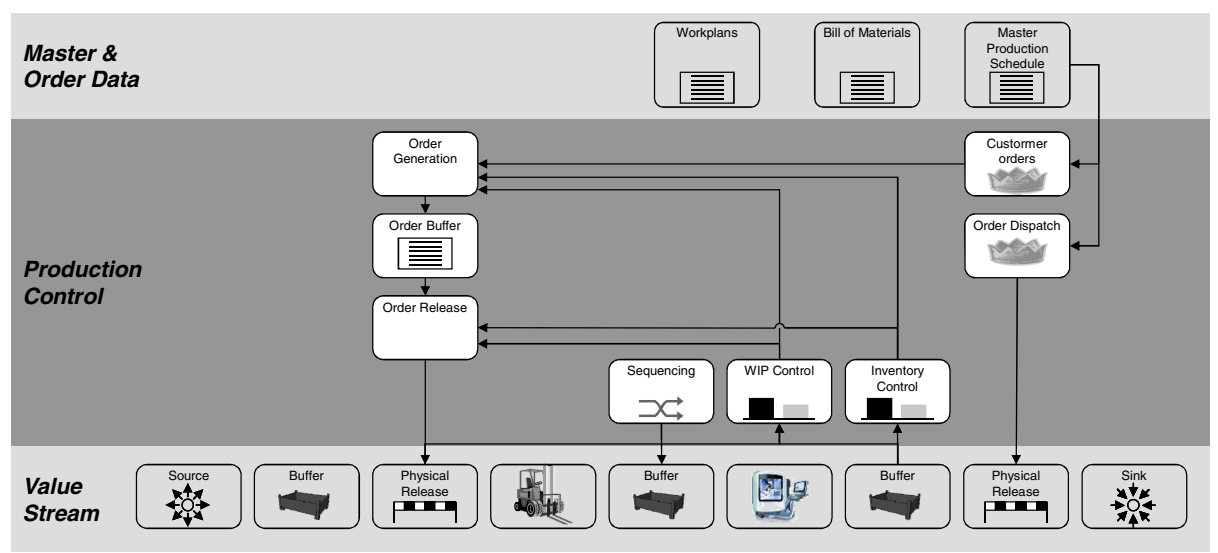

Fig. 1. The three layers model of production control

Only by including all parameters of the production control, it is possible to find a customized and optimized configuration for a company. That is the reason why the value stream oriented production control approach determines the influence of the configuration of the production control on logistic performance factors (inventory, delivery accuracy, throughput time, capacity utilization) as a whole.

\section{$2 \quad$ Right Adjustment and Understanding of Production Control}

In the wake of the rapid development of information technology and information management in production systems, Advanced Planning and Scheduling (APS) systems are used more and more often to plan and to control production processes. The basic idea of these systems is to make use of real-time feedback from production to adapt the production schedule continuously to any kind of disturbances [12]. Due to continuously changing conditions, the program may possibly reject several scheduling proposals made within one day as they lead to chaos within the production and distrust in the planning system. Often, the result is a redundant reschedule of the employees.

It is questionable whether a high-frequent intervention in the production process is beneficial. The funnel-experiment by Deming shows that there is a maximum amount of reasonable interventions within process operations. Within this experiment, balls are dropped through a funnel on a calibrated surface [13]. Thereby, the scattering of points of impact is measured in relation to the target impact. The results of this experiment show the influence of interventions on the scattering: the more interventions were undertaken by the operator, the higher was the scattering of points of impact. These findings can be transferred to production control: in order to avoid a turbulent production, the optimal amount of interventions and the improvement of the production system are crucial to be found. Systemic process variations or rather the scattering of the points of impact within the experiment cannot be reduced by permanent correction of the funnel-position. A reduction of the scattering can only be achieved by a dedicated improvement of the system. 
In addition to the right adjustment of production control, employees have to be involved within decision process. Since the options of different configurations in production control are enormous, a number of predictably irrational decisions are made [14]. For instance, qualitative or quantitative models do, up to now, not universally analyse the effectiveness of priority rules for order sequencing [15]. Despite numerous studies there is a need for a stronger generalization for industrial environments. Furthermore, many employees do not understand the influence of work in process on throughput times. This lack of knowledge leads to an on-going, controversial debate about the effects of different control methods among practitioners. The insufficient achievement of logistic targets is therefore caused by a lack of knowledge of the operators [16]. Consequently, counterproductive decisions lead to a poor performance of logistic targets in production. The most common pitfalls leading to such behaviour are for example the wrong understanding of pull or push principles, especially regarding to the impact of work in process [17]. The results of several industry cases of the Laboratory for Machine Tools and Production Engineering (WZL) have shown, that simple structural solutions like first-in-first-out production is often more successful regarding the achievement of logistic targets than is a complicated APS system which is not understood and supported by its operators.

Therefore, the interaction of production structure and production control has an important bearing on the efficiency of production. This interaction is not sufficiently described in literature so far. Often, different adjustments cannot be tested in operation and results of simulation cannot be used because of the non-comparability of existing models [18]. In existing simulation studies, different models are exclusively designed. Hence, the results of these studies are not comparable and cannot be used to derive adequate statements about production control. The usage of a low amount of working systems and product variants is followed by a characteristic and low complexity of these systems [19]. Therefore, an analysis of a universal production system model is needed in order to analyse the effects of production structure and production control on logistic targets sufficiently.

\section{State of the Art: Analyzing the Effects of Production Structure and Production Control on Logistical Targets Using Simulation}

The aim of this paper is to design a model which ensures an analysis of the effects of production structure and production control on logistical targets in a general way. According to Rabe, the following steps have to be defined in order to generate the simulation model [20]:

At first, the definition of the target system determines command variables to be analysed within the simulation. To obtain meaningful results, these command variables can be determined as averages or standard deviation. In this context, logistic targets like utilization, work in process, cycle time, adherence to delivery times and compliance of sequence shall be analyzed. In addition, the focus should be on changing the sequence, which can be seen as a performance indicator for the deviation of sequencing.

In a second step, system boundaries, system variables, subsystems and elements of the simulation model have to be defined. The definition of system boundaries includes the material and information interfaces to its environment. In order to analyze single tasks of production control, it is necessary to narrow the system with a dedicated 
control task to focus on. The result of such a system analysis is a clarification of the system, the organizational structure and the flow structure (see Fig. 2). In this example, the focus is on analyzing the influence of sequencing rules.

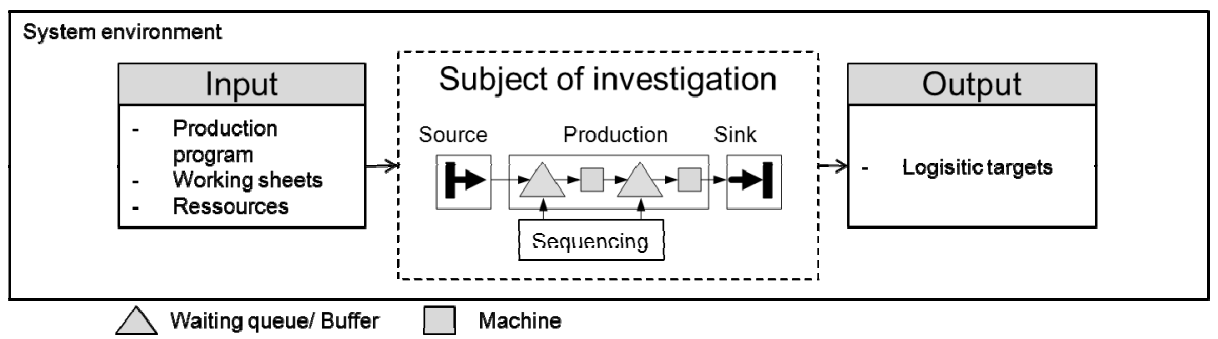

Fig. 2. System environment of simulation model

Then, the collection and preparation of data and information like manufacturing principle, material flow, production type, amount of variants and complexity of material flow as well as system load is needed. Important information for the analysis of effects of a changing production structure is lot sizes. Since there is a trend to more product variants and smaller production volume, levelling of lot sizes supports decoupling of production and customer demand in order to achieve a harmonized production [21].

Based on the system analysis and collection of the database, a simulation model with the purpose to analyse the defined task can be designed. Here again, this is shown using the example of different sequencing rules. The simulation evaluates the achievement of logistic targets regarding different settings of the production structure und production control. Concerning throughput time (see Fig. 3) for instance, the result of the simulation provides a ranking of the sequencing rules, used in this simulation model. The result of the simulation also underlines the success of a sequencing rule which prioritizes orders with the shortest operating time (SOT). For this sequencing rule, the average throughput times are the lowest. The second best rule within the simulation is a sequencing rule which combines orders with the aim of reducing setup times. Finally, this one is followed by the sequencing rule of slippage, which indicates the amount of time until planned delivery date that is not required for further production or transport.

In this case, the first three steps of lot size levelling deteriorate average throughput times. Only the ideal scenario represents an improvement of throughput times. This effect is due to bottlenecks. Therefore, the results of the simulation have to be evaluated with consideration to these bottlenecks. With respect to the simulation model, further scenarios have to be simulated in order to analyse the effects of changing bottlenecks.

As shown, the simulation-based approach, in this case done with the simulation tool "PlantSimulation" (by Siemens), facilitates an evaluation of production control principles with regard to a certain production structure. The results of the presented simulation model show a ranking of sequencing rules regarding different levels of lot size levelling. Thus, it represents an important analysis of interaction of production structure and production control. The benefits are on the one hand the possibility to compare certain production control methods and on the other hand the evidence of the impact of production structure in order to maximize the production systems' targets. 


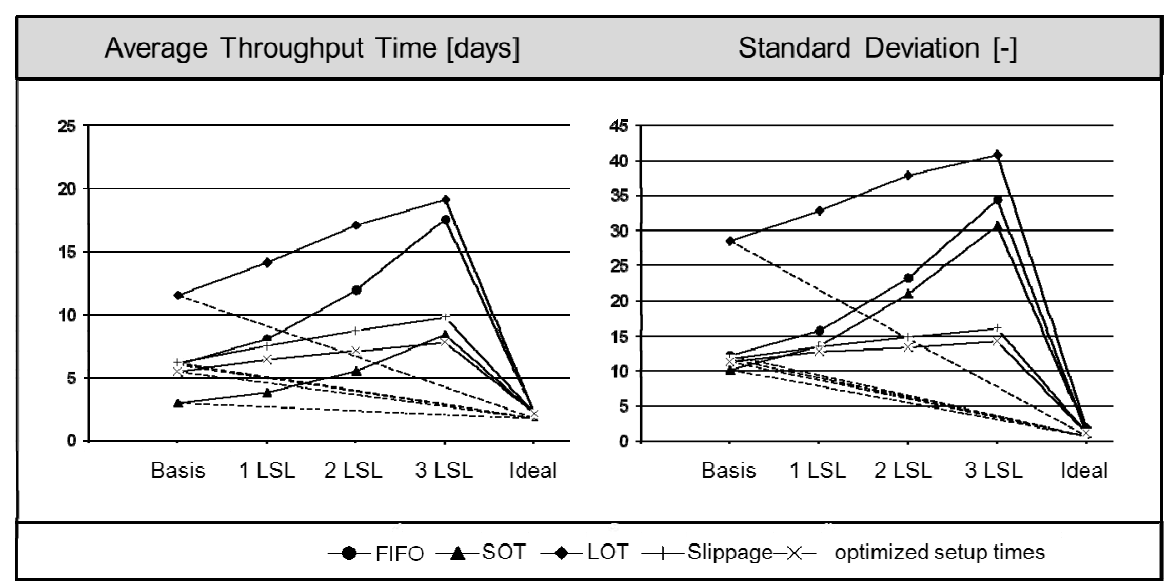

Fig. 3. Example of simulation results regarding throughput times

Despite the benefits of simulation-based approaches for production control, the modelling process of high quality models is still time consuming and in addition requires expert knowledge in different areas. Consequently, carrying out simulation projects is linked with high costs, which makes it an issue especially for smaller and middle sized companies. Once set up, the models have to be verified. This is an iterative process as, referring to chapter 2, adjustments cannot be made in operation. Even in case the models turn out to be accurate, a broader understanding of their mode of functioning has to be installed amongst employees. A lack of transparency and understanding often deteriorates acceptance. Also the fact that simulating results often turn out not to be comparable, as the underlying model has been designed for a special environment, does not contribute to acceptance.

Consequently there is the challenge of finding a certain degree of standardization in the simulation process and therefore of allowing also non-experts to make use of simulating tools.

\section{Approach of a Web Based Simulation Model}

In order to face the challenge described above, a web-based framework has been developed which takes the idea of simulating to another level. The main idea of this web-based simulation model is a modular structure with a user-friendly interface. Ths user is able to upload input data easily and to configure production control by just pressing buttons. Thereby, no simulation knowledge is needed because the simulation takes place in the background of this model. The web-based surface is structured by a field for input data, a field for the configuration of production control and a field for the results of the simulation (see Figure 4). 

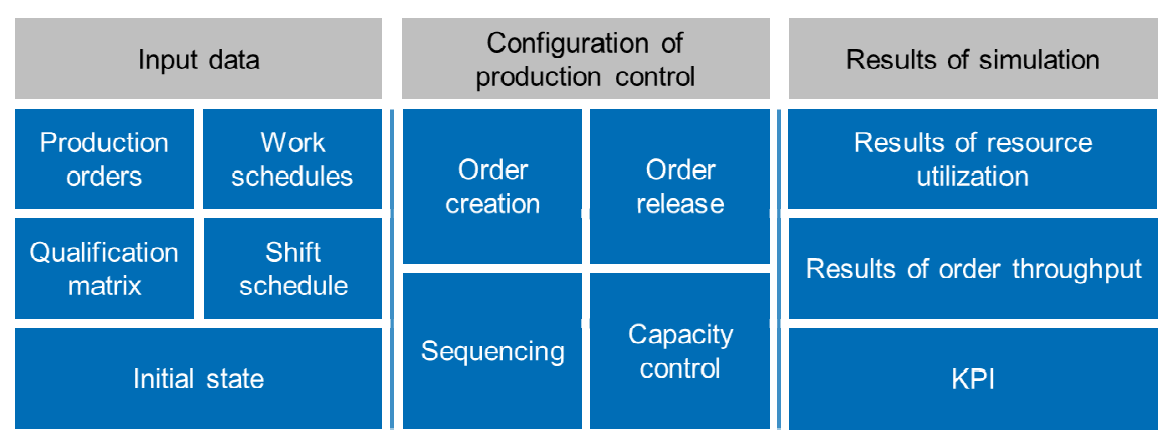

Fig. 4. Mock-up of web-interface of simulation

Simulation input data are in general work schedules, production orders and shift schedules for example. These data are provided by Enterprise Resource Planningsystem (ERP). Based on these input data, the resources and orders for simulation can be generated automatically within the simulation model. Based on shift schedule and qualification matrix, availability of employees is covered. This is important in order to model flexible employment in case operators get sick for instance. The initial state of simulation is given by the production data from ERP-system. Since input data are in general historical feedback data from production for a certain time period, the initial state can be exemplary derived by the order mixture at a certain date.

After uploading input data, configuration of production control strategies is done by defining the four tasks of production control. This procedure follows the concept of value stream oriented production control (see chapter 1.3). While the production structure is represented by the value stream and production program, the production control can be selected manually by using the web-based surface of simulation model. Thereby, the control strategies can be allocated to the machines. This allocation is done by drag and drop, so there is no simulation knowledge necessary. The operator just interacts with the web-based user interface while the simulation is running in the background of the system.

Then, the simulation can be started. The results of simulation represent logistic targets of production like the resource utilization and the throughput of orders etc. The results are also presented on web-surface which enables the user to interactively analyze the results.

\section{$5 \quad$ Conclusion and Outlook}

The simulation-based approach facilitates an evaluation of production control principles in regard to a certain production structure. By using the web-based simulation model, no simulation expert knowledge is required. The advantage of this web-based value stream oriented simulation model is its modular structure and its simple adaptability. Thus, the impact of different control methods for a certain production structure can by analyzed. By deriving arrangements, production system's targets can be maximized. By integration of employees within the simulation generation process, the acceptance in simulation and in simulation results increases. 
The next step is to develop a optimization of production control automatically by exchanging the described control modules for job creation, job release, sequencing and operational capacity control. The user will be able to automatically receive the optimized controlling and sequencing parameters as well as their optimization potential. This will be done with the help of genetic algorithms. Therefore, the user has to describe its optimization goal like e.g. delivery accuracy or throughput time.

Acknowledgements. The concept of manufacturing control with consideration of production structure is one part of the framework developed within the excellence initiative "Integrative production technology for high wage countries" at Aachen University as a part of the "High Resolution Supply Chain Management" cluster. The main research objective is to develop decentralized production planning and controlling concepts and to develop new solutions for existing PPS concepts.

\section{References}

1. Ulrich, H.: Der systemorientierte Ansatz in der Betriebswirtschaftslehre. In: Kortzfleisch, G. (ed.) Wissenschaftsprogramm und Ausbildungsziele der Betriebswirtschaftslehre, 1st edn., pp. 45-49. Duncker und Humblot, Berlin (1971)

2. Ulrich, H., Schwaninger, M.: Systemorientiertes Management. Das Werk von Hans Ulrich, p. 14. Paul Haupt Verlag, Bern (2001)

3. Ropohl, G.: Allgemeine Technologie: Eine Systemtheorie der Technik, 3rd edn. Universitätsverlag Karlsruhe, Karlsruhe (2009)

4. Jones, D.: Creating Lean Solutions, 2. Lean Management Summit, Aachen, Germany, pp. 17-28 (2005)

5. Milberg, J., Neise, P.: Organizational Design of Supply Chains. WGP, Production Engineering XIII/2, 181-186 (2006)

6. Wiendahl, H.-P.: Betriebsorganisation für Ingenieure, 4th edn. Hanser (1997)

7. Goldratt, E., Cox, J.: The Goal: Excellence in Manufacturing. North River Press, Crotonon-Hudson (1984)

8. Petermann, D.: Modellbasierte Produktionsregelung. Fortschittsberichte VDI, Reihe 20, Nr. 193, Düsseldorf, p. 1 (1996)

9. Lödding, H.: Verfahren der Fertigungssteuerung, 2nd edn. Grundlagen, Beschreibung, Konfiguration. Springer, Berlin (2008)

10. Schuh, G., Franzkoch, B., Potente, T., Fuchs, S.: Simulation based configuration of value stream oriented production control. In: Conference Proceedings, POM 21st Annual Conference, POM 2010 Conference Program Bulletin, Vancouver (2010)

11. Schuh, G., Kampker, A., Potente, T., Stollwerk, A., Müller, C.: Wertstromorientierte Konfiguration der Produktionssteuerung mit Enterprise Dynamics (Value stream oriented configuration of the production control with Enterprise Dynamics. In: Zülch, G., Stock, P. (eds.) Integrationsaspekte der Simulation: Technik, Organisation und Personal, pp. 413-420. KIT Scientific Publishing, Karlsruhe (2010b)

12. Zijm, W.H.M.: Towards Intelligent Manufacturing Planning and Control Systems. Journal OR Spectrum 22(3), 313-345 (2000)

13. Deming, W.E.: The New Economics: for industry, government, education, 2nd edn., p. 190. Center of Advanced Educational Services, Cambridge (1994) 
14. Schuh, G., Lenders, M., Nussbaum, C., Kupke, D.: Design for Changeability. In: ElMaraghy, H. (ed.) Changeable and Reconfigurable Manufacturing Systems. Springer, London (2008)

15. Nyhuis, P., Hartmann, W., et al.: Der Einfluss von Prioritätsregeln auf logistische Zielgrößen. Productivity Management 14(3), 17-20 (2009)

16. Nyhuis, P.: Beiträge zu einer Theorie der Logistik. Springer (2008)

17. Schuh, G., Franzkoch, B., Potente, T., Fuchs, S.: Simulation based configuration of value stream oriented production control. In: Conference Proceedings, POM 21st Annual Conference, POM 2010 Conference Program Bulletin, Vancouver (2010)

18. Framinan, J.M., et al.: Input control and dispatching rules in a dynamic CONWIP flowshop. International Journal of Production Research 38(18) (2000)

19. Day, J.E., Hottenstein, M.P.: Review of sequencing research. Naval Research Logistics Quarterly 17, 11-39 (1970)

20. Rabe, M., Spieckermann, S., Wenzel, S.: Verifikation und Validierung für die Simulation in Produktion und Logistik. Springer, Heidelberg (2008)

21. Deuse, J.: Entwicklung einer systematischen Vorgehensweise zur Produktionsnivellierung der variantenreichen Kleinserienfertigung. AiF-Schlussbericht 15865 N/1 (2010) 